\title{
Multiple Objective Fuzzy Sourcing Problem with Multiple Items in Discount Environments
}

\author{
Feyzan Arikan \\ Department of Industrial Engineering, Gazi University, Maltepe, 06570 Ankara, Turkey \\ Correspondence should be addressed to Feyzan Arikan; farikan@gazi.edu.tr
}

Received 23 July 2014; Revised 4 December 2014; Accepted 4 December 2014

Academic Editor: Tsan-Ming Choi

Copyright (C) 2015 Feyzan Arikan. This is an open access article distributed under the Creative Commons Attribution License, which permits unrestricted use, distribution, and reproduction in any medium, provided the original work is properly cited.

\begin{abstract}
The selection of proper supply sources plays a vital role to maintain companies' competitiveness. In this study a multiple criteria fuzzy sourcing problem with multiple items in discount environment is considered as a multiple objective mixed integer linear programming problem. Fuzzy parameters are demand level and/or aspiration levels of objectives. Three objective functions are minimization of the total production and ordering costs, the total number of rejected units, and the total number of late delivered units, respectively. The model is developed for the all-units discount scheme. For the incremental discount and volume discount environment, modification requirements of the model are mentioned. The previously proposed interactive fuzzy approach combined with three fuzzy mathematical models is employed to obtain most satisfactory solution which is also a nondominated one. This study provides a realistic mathematical model and promising solution strategy to multiple item-single period sourcing problem in discount environment. Consideration of fuzziness makes the obtained nondominated solution implementable for the real cases.
\end{abstract}

\section{Introduction}

In many industries, raw material costs, components, and parts purchased from suppliers constitute a major amount of the overall production costs. The suppliers having the required performance levels in price, delivery, quality, and service strictly improve both cost and operating effectiveness of companies. Hence, the selection of proper suppliers plays a vital role to maintain companies' competitiveness. Selection decision of suppliers determine "how many and which suppliers are the best, sourcing," and "how much should be purchased from each selected supplier, the order allocation among the suppliers." The sourcing and order allocation is a multicriteria decision making problem which includes both qualitative and quantitative factors some of which may conflict. Dickson [1] identified 23 criteria that have been considered by purchasing managers in various supplier selection problems. In addition to multicriteria nature of the problem, informational vagueness because of the tangible and intangible factors of supplier selection problems is another significant fact which must be taken into account to reach effective and implementable solutions.
Another important aspect related with the real world supplier selection problems is to encounter price discounts offered by suppliers in order to encourage the buyers to select them and/or to buy larger quantities [2]. Although there are various kinds of discount contracts in practical applications, they can be investigated under two headings (Table 1) based on the physical and the informational flows in a supply chain [3]. According to the physical flow, the most common discount schemes are business volume discount and quantity discount depending on the volume being purchased and depending on the order size, respectively. Based on the informational flow in a supply chain, Sirias and Mehra [3] mentioned that lead time-dependent discount scheme is a promising strategy.

Business volume discount is used when more than one item is to be purchased. In this scheme supplier offers discounts on the total price of sales volume, not on the quantity or variety of the products purchased.

In the context of quantity discount, the sales volume of a product does not affect the prices and discounts of the other products [4]. In this scheme, single item or multiple items can be considered. Three common types of quantity discount 
TABLE 1: Classification of discount schemes.

\begin{tabular}{|c|c|}
\hline $\begin{array}{l}\text { Discounts based on physical flows } \\
\text { in a supply chain }\end{array}$ & Reference \\
\hline Business volume discount & {$[7,8]$} \\
\hline Quantity discount & $\begin{array}{l}\text { (1) Linear quantity discount } \\
{[5,6]} \\
\text { (2) Cumulative-all-units } \\
\text { quantity discount (AQD) } \\
\text { (3) Noncumulative-incremental } \\
\text { quantity discount (IQD) } \\
\text { Detailed literature see in [3] }\end{array}$ \\
\hline Bundling & {$[9-11]$} \\
\hline $\begin{array}{l}\text { Deferred rebates based on total } \\
\text { value of order } \\
\text { Deferred rebates based on the } \\
\text { order quantity } \\
\text { Marginal discounts based on the } \\
\text { total value of the order }\end{array}$ & {$[12]$} \\
\hline \multicolumn{2}{|l|}{$\begin{array}{l}\text { Discounts based on informational } \\
\text { flows in a supply chain }\end{array}$} \\
\hline Lead-time dependent discount & Detailed literature see in [3] \\
\hline
\end{tabular}

strategies are linear quantity discount, all-units discount, and incremental-units discounts $[5,6]$. The linear quantity discount strategy assumes that each supplier offers a linearly declining per unit price within the capacity range. Related with this strategy Burke et al. [5] mentioned that, for the case where each supplier has adequate capacity to meet the aggregate requirement of the customer, then the single sourcing will be the best decision for the customer when the objective function is to minimize the total costs. Hence in the literature quantity discount strategy has been often considered as if it can be either cumulative (all-units) or noncumulative (incremental). In all-units quantity discount (AQD), once an order size exceeds a predetermined quantity threshold, the suppliers can offer a discount that lowers the wholesale price on every unit purchased. There may be many such intervals, defined by the threshold values which are called price-break quantities. With a number of price breaks, the unit discounted price decreases as the quantity level increases. In incremental quantity discount (IQD), the discount rates are incrementally applied over the volumes for each interval; thus different prices are applied to the units belonging to different price breaks.

According to the physical flow another discount scheme is freight rate discount scheme offered by shippers $[13,14]$. While quantity discount considers unit price, freight rate discount considers unit shipment and it can be offered according to all units (called all weights) or incremental strategies [15].

Apart from the business volume discount and quantity discounts, in the lead time-dependent discount scheme, supplier(s) offer a number of time intervals during the planning horizon to fulfill orders where in each interval more lead time corresponds to a price discount. A practical situation of such lead time dependent discount schemes can be found in chemical, semiconductor, and automotive industries where suppliers and customers engage in flexible quantity contracts that envision different pricing and capacity availabilities depending on lead times [16].

In this study the sourcing and order allocation problem is considered as a multiple objective decision making problem with vague parameters in price discount environment. Three objective functions are minimization of the total purchasing and ordering costs, the total number of rejected units, and the total number of late delivered units, respectively. Fuzziness stems from the problem parameters which are demand level and/or aspiration levels of objectives. Fuzzy parameters are described with linear membership functions according to the decision maker (DM)'s preference. All-units discount scheme is considered in the main mathematical model. For the incremental discount and volume discount environment, modification requirements of the model are mentioned. Three fuzzy mathematical models are employed separately to obtain most satisfactory solution which is also a nondominated one. The fuzzy decisions are defined by the add operator [17] in two of the models and in the third fuzzy model it is defined by the augmented max-min operator $[18,19]$.

The remainder of the paper is organized as follows. In Section 2, literature is reviewed in detail and the contribution of this study is revealed. In Section 3, the considered multiple objective supplier selection model is explained in crisp form. In Section 4, after preliminary definitions of fuzzy mathematical programming, fuzzy additive model [17], augmented max-min model [18, 19], and Chen and Tsai's [20] fuzzy model for the considered supplier selection problem are defined. In Section 5 the interactive solution methodology which combines these three fuzzy mathematical models is summarized. In Section 6, the solutions of each fuzzy model are presented for an illustrative example problem based on the interactive methodology. Conclusions and future directions appear in the final section.

\section{Literature Review}

Supplier selection problem has been a focus area of research since 1960. Reviews of supplier selection criteria and methods can be found in review studies which belong to Weber et al. [21], Degraeve et al. [22], De Boer et al. [23], Aissaoui et al. [4], and Ho et al. [24]. A detailed classification and review of qualitative techniques for supply chain planning under uncertainty can be found in Peidro et al.s [25] review paper. Recently, Chai et al. [26] reviewed the studies on the application of the decision making techniques for supplier selection from 2008 to 2012 .

The quantitative techniques for supplier evaluation and selection can be categorized into three classes [27]: (1) multiple attribute decision making, (2) mathematical programming models, and (3) intelligent approaches. Multiple attribute techniques commonly employed to select and/or rank suppliers (e.g., [28]) or to determine of the weights of the objectives (e.g., $[29,30])$. In the former case to allocate orders among suppliers, mathematical programming has been utilized additionally.

Among the quantitative techniques, mathematical programming models have been extensively used for the sourcing 
and order allocation problem. The models can be either single period that do not consider inventory management or multiperiod models which consider the inventory management by lot-sizing and scheduling orders. Single period models come handy in make-to-order manufacturing where custom parts are critical meanwhile common parts are efficiently managed by material requirement planning methods. The custom parts need to be requisitioned with each customer order and hence the custom parts inventory needs not to be considered [31].

Since Weber and Current [32] introduced a multiobjective mixed integer programming model for supplier selection and order allocation among the selected suppliers, several authors [29, 33-37] proposed multiple objective programming models to this problem. Objective functions are constructed based on four basic supplier evaluation criteria as price, quality, customer service, and delivery [38].

In literature a few of the studies have addressed both multiple objectives and fuzziness in the problem. Arikan [3840] investigated and classified the fuzzy multiple objective sourcing and order allocation studies based on mathematical modelling in the literature, which have employed five solution approaches which are Zimmermann's [41] max-min approach [27, 42-44]; Tiwari et al's [17] additive model [27, 45-50]; fuzzy goal programming with weights [30]; fuzzy programming with modified fuzzy or operator [51]; and sequential quadratic programming [52]. Arikan [38] mentioned the disadvantages of these methods in detail: sequential quadratic programming does not consider objectives simultaneously. Zimmermann's max-min approach does not guarantee a nondominated solution. Although the rest of the approaches guarantee a nondominated solution, none of them is interested in a balanced solution. Tiwari et al.s additive model maximizes achievement levels in total and the solution may include zero level achievement(s). Then an unbalanced fuzzy optimal solution is obtained [53]. Fuzzy goal programming with weights and fuzzy programming with modified fuzzy or operator do not prohibit the unbalanced solution case either. To handle all these criticisms, Arikan [38] employed Lai and Hwang's augmented max-min approach $[18,19]$ to fuzzy multiple objective supplier selection problem to obtain a solution which is both a nondominated and balanced one. In multiple objective decision making problems, obtaining "a best compromise solution" is an important matter of fact. The best compromise solution is the most preferred solution by the DM in the nondominated solution set [39]. For the real cases, preferences of $\mathrm{DM}(\mathrm{s})$ can be various and they may not point out a balanced solution. From this point of view, Arikan [39] proposed a two-phased approach which utilizes Chen and Tsai's [20] fuzzy model to satisfy the DM's preferred achievement levels. Utilizing Chen and Tsai's fuzzy model solely may result in "no feasible solutions" when a DM requires a very high desirable achievement degree for each fuzzy goal. In the two-phased approach, in order to prevent infeasible solution case the additive model solution is represented to the DM during the selection process of the minimum acceptable achievement levels. Afterwards Arikan [40] combined the previous works $[38,39]$ to accommodate an efficient interactive approach in which augmented maxmin model [18, 19], additive or weighted additive model [17], and Chen and Tsai's [20] fuzzy model are employed interactively to obtain a nondominated solution to reach the DM's preferences [40]. Although this fuzzy interactive approach was generated based on the fuzzy multiple objective supplier selection problem requirements, it can be employed for any type of multiple objective programming problems by considering four different cases based on the sources of fuzziness.

Among the above-mentioned studies which have addressed both multiple objectives and fuzziness in the problem, Amid et al's study [46] is the only one which considers price discounts. However, it is concentrated on a single item sourcing problem and utilized Tiwari et al.s [17] weighted additive model which may result in an unbalanced solution.

Discounts are fundamental pricing strategies in numerous industries. Hence there is a substantial amount of literature related to the discount problem. One of the early cornerstone papers in the area is Dolan's [54] in which quantity discounts schemes are classified and analyzed to provide a guideline to managers. Benton and Park [55] classified the literature on determining the lot size under quantity discount. Recently Setak et al. [56] review the literature based on the supplier selection and order allocation models for the period 2000-2010 years. They classified supplier selection models with and without discount environments.

Three steams of literature which are related to this current study are multiple criteria, fuzziness, and discount strategies. Herein, the literature is restricted with the studies concentrated on fuzzy multiple objective sourcing and order allocation problem in the presence of discount schemes as mixed integer programming model. Both single and multiple period models are investigated. In the literature the following seven studies (Table 2) consider fuzzy multiobjective supplier selection problem in the presence of discount schemes as mixed integer programming problem: Nazari-Shirkouhi et al.s [57], Kang and Lee's [58], Razmi and Maghool's [59], Amid et al.'s [46], and Torabi and Hassini’s [16, 60] studies and Arikan's [2] study.

Razmi and Maghool [59] solved a multiple item-multiple period multiple objective programming model by the lexicographic approach. In other words they considered each objective one at a time. The models utilized in the other four studies considered objectives simultaneously and generated nondominated solutions: Kang and Lee [58] considered a single item-multiple period model. Amid et al. [46] considered a single item-single period model. Both Kang and Lee [58] and Amid et al. [46] performed Tiwari et al.s [17] weighted additive model which may result in unbalanced solutions. Torabi and Hassini $[16,60]$ considered multiple item-multiple period models and suggested interactive approaches in which augmented max-min model and Werner's fuzzy or model are utilized. Although augmented max-min model gives a balanced solution, for some real cases DM may not be interested in a balanced solution, and reaching his/her preferred minimum achievement levels is more important for him/her as long as the solution is a nondominated one. Fuzzy model with Werner's fuzzy or operator has $\gamma \in[0,1]$ parameter which represents the compensation level. When $\gamma=0$, the model becomes equivalent to the additive model; when $\gamma=1$, then the model becomes equivalent to Zimmermann's max-min 


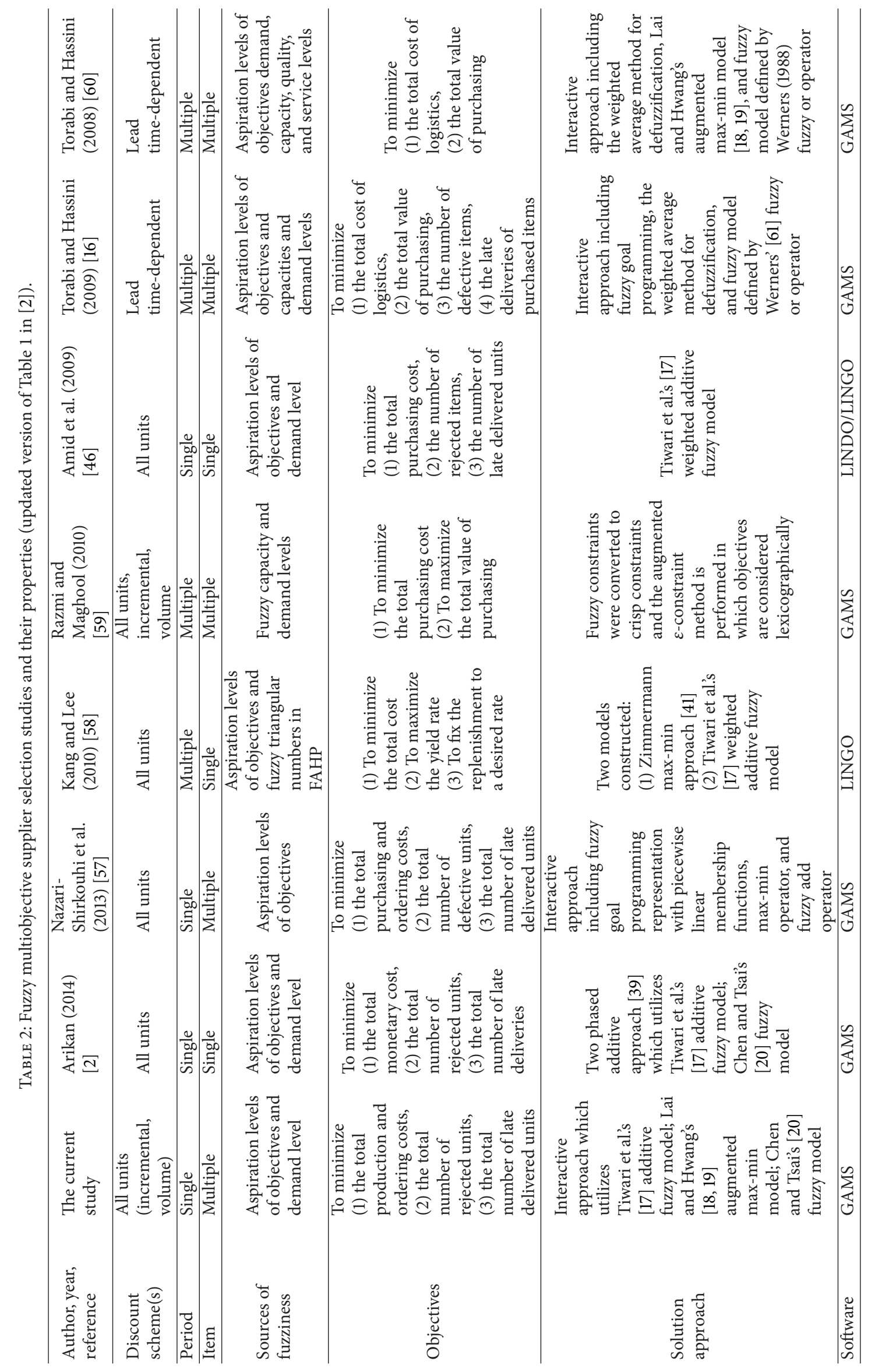


model [41]. Determination of gamma parameter makes the model implementation harder [38]. Arikan [2] considered a single item-single period multiple sourcing problem in the presence of all-units discount scheme and solved it by the two-phased approach proposed in [39]. In that study [2], a mixed integer mathematical model based on Amid et al's [46] study is solved to obtain the DM's preferred achievement levels.

In the literature there is no multiple item-single period fuzzy model except for the Nazari-Shirkouhi et al.s [57] to our knowledge. In their study, fuzziness stems from the goals attained to objectives whereas demand levels were considered in crisp sense. They represented fuzzy goals mathematically by piecewise linear membership functions. Nazari-Shirkouhi et al. [57] utilized a two-phase fuzzy goal programming approach. The detailed classification and criticism of the existed fuzzy goal programming approaches in the literature can be found in Arikan's [62]. Nazari-Shirkouhi et al.s [57] approach is the goal programming version of Lee and Li's [53] approach. Lee and Li [53] developed a two-phase approach to improve the feasible but dominated solution yielded by min operator. In the first phase of the approach, Zimmerman's max-min approach is used. In the second phase of the approach a fuzzy model by using arithmetical average aggregating operator for the same problem is constructed with a lower bound restriction which is the solution of the first fuzzy model. The approach requires two phases to obtain a nondominated solution. In the second phase fuzzy additive model utilizes with a lower bound restriction which is the solution of the first fuzzy model. Although that lower bound restriction prevents the occurrence of an unbalanced solution, the approach does not satisfy the DM's preferred achievement levels, surely if there exist.

In this study, fuzzy sourcing and order allocation problem with multiple items and multiple suppliers in discount environment is considered. The aim of the study is to reach a nondominated solution to satisfy the DM's preferred achievement levels. The detailed investigation of the literature shows that the studies were disregarded to satisfy the DM's preferred achievement levels for the mentioned problem. In that case, previously proposed interactive approach [40] comes handy not only to reach the aim of this study but also to consider the different cases for the fuzzy parameter occurrences and the DM's different bias on the nondominated solution. Another important fact related with the interactive approach is that each fuzzy model utilized in the approach guarantees a nondominated solution separately. Interactive steps of the approach let the DM incorporate (modify) his/her preferences during the solution process. The significantly important traits of the DM such as experience, knowledge, ability, and foresight can be included into the decision process by interactivity even when the analyst and the DM are not the same person. The mathematical model of the considered problem is constructed as a linear 0-1 mixed integer programming model based on [57] with additional constraints and variations for different discount schemes. Fuzziness stems from fuzzy demand levels for each or some product(s). Objectives' aspirations can be fuzzy or crisp. Fuzziness is defined mathematically by using linear membership functions. Fuzzy demand(s) are assumed to be triangular number(s). Based on the considered interactive solution procedure [40], the DM preferred achievement levels are satisfied with a nondominated solution.

\section{Multiobjective Supplier Selection Model with Price Breaks}

In this study a linear 0-1 mixed integer model based on [57] is considered for supplier selection problems with multiple products and the all-units discount scheme. The proposed model restricts the number of suppliers employed by the buyer with a maximum number quota for each product as well. The model is as follows:

$$
\begin{aligned}
\operatorname{Min} z_{1} & =\sum_{i \in I} \sum_{j \in J} \sum_{k \in K} P_{i j k} x_{i j k}+\sum_{i \in I} \sum_{j \in J} F_{i j} y_{j}, \\
\operatorname{Min} z_{2} & =\sum_{i \in I} \sum_{j \in J} \sum_{k \in K} q_{i j k} x_{i j k}, \\
\operatorname{Min} z_{3} & =\sum_{i \in I} \sum_{j \in J} \sum_{k \in K} t_{i j k} x_{i j k}
\end{aligned}
$$

subject to

$$
\begin{aligned}
& \sum_{j \in J} \sum_{k \in K} x_{i j k}=D_{i}, \quad \forall i ; \\
& y_{i j k} \leq x_{i j k} \leq C_{i j} y_{i j k}, \quad \forall i, j, k ; \\
& V_{i j k-1} y_{i j k} \leq x_{i j k} \leq V_{i j k} y_{i j k}, \quad \forall i, j, k, \\
& \sum_{k \in K} y_{i j k}=w_{i j}, \quad \forall i, \forall j, \\
& \sum_{j \in J} w_{i j} \leq N_{i}, \quad \forall i, \\
& y_{j} \leq \sum_{i} \sum_{k} y_{i j k} \leq m y_{j} \quad \forall j, \\
& \sum_{k \in J} y_{i j k} \leq 1, \quad \forall i, j, \\
& \sum_{j \in J} e_{i j} \sum_{k \in K} x_{i j k} \geq E_{i} D_{\dot{I}}, \quad \forall i ; \\
& \sum_{j \in J} s_{i j} \sum_{k \in K} x_{i j k} \geq S_{i} D_{\dot{I}}, \quad \forall i ; \\
& \sum_{j \in J} r_{i j} \sum_{k \in K} x_{i j k} \geq R_{i} D_{\dot{I}}, \quad \forall i ; \\
& x_{i j k} \geq 1 \quad \forall i, j, k \text { and integer, } \\
& y_{j}, y_{i j k}, w_{i j} \in\{0,1\}, \quad \forall i, \forall j, \forall k,
\end{aligned}
$$

where $i$ is index for products, $j$ is index for suppliers, and $k$ is index for quantity discount levels.

Decision variables:

$x_{i j k}$ is the number of units of product $i$ ordered from the $j$ th supplier at discount level $k$; 
$y_{i j k}$ is 1 if product $i$ is ordered from supplier $j$ at discount level $k$; 0 , otherwise;

$w_{i j}$ is 1 if product $i$ is ordered from supplier $j ; 0$, otherwise;

$y_{j}$ is 1 if at least one product is provided from supplier $j$; 0 , otherwise.

\section{Parameters:}

$D_{i}$ is the aggregate demand of the product $i$ from all suppliers over a fixed planning period;

$P_{i j k}$ is the per unit net purchase cost of product $i$ from supplier $j$ at discount level $k$;

$F_{i j}$ is the fixed ordering cost for product $i$ from supplier $j$;

$q_{i j k}$ is the percentage of the rejected units of product $i$ delivered by the supplier $j$, at discount level $k$;

$t_{i j k}$ is the percentage of the late units of product $i$ delivered by the supplier $j$, at discount level $k$;

$C_{i j}$ is the capacity of $j$ th supplier for product $i$;

$V_{i j k}$ is the maximum purchased volume of product $i$ from the $j$ th supplier at $k$ th discount level;

$N_{i}$ is the maximum number of suppliers that can be selected for product $i$;

$E_{i}$ is the lower bound of quota flexibility required by $i$ th product;

$S_{i}$ is the lower bound of service level required by $i$ th product;

$R_{i}$ is the lower bound of rating value required by $i$ th product;

$e_{i j}$ is the flexibility of supplier quota allocation of $j$ th supplier for $i$ th product;

$s_{i}$ is the service level required by $i$ th product;

$r_{i}$ is the rating value required by $i$ th product.

Objective function (1) minimizes total purchasing and fixed ordering costs. Objective function (2) minimizes the total number of rejected units, which serves in maximizing total quality of purchased items. Objective function (3) minimizes the total number of late delivered units, which serves in maximizing the service level of purchased items. Constraint (4) ensures that the overall demand is satisfied. Constraint (5) means that order quantity of each supplier should be equal to or less than its capacity. Constraint (6) ensures that the number of units purchased from supplier $j$ is placed in the appropriate discount interval for each item. Constraints (7) and (8) restrict the number of suppliers employed by the buyer with a maximum number quota for each product. Constraint (9) means all the products purchased from the same supplier are placed in one order. It is calculated for the fixed ordering cost in objective (1). Constraint (10) ensures only one discount level is eventually used for the amount if product $i$ is purchased from supplier $j$. Constraints (11)-(13) represent that the quota flexibility, service level, and rating values must exceed a given level. Constraint (14) prohibits negative orders. Constraint (15) presents binary integer variables.

The following two modifications on the above model ((1)(15)) are needed when suppliers offer incremental and volume discount schemes, respectively. In both cases considering suppliers' offers, the buyer makes decision to minimize the total purchase cost in addition to the other two objectives defined formerly subject to the same constraint set.

When suppliers offer incremental discount scheme, the above formulation can be modified with formulation (16) instead of (1):

$$
\begin{aligned}
\operatorname{Min} z_{1}=\sum_{i} \sum_{j}\left(\sum_{m=1}^{k-1} p_{i j m}\left(V_{i j m}-V_{i j, m-1}\right)\right. & \\
& \left.+p_{i j k}\left(x_{i j k}-V_{i j, k-1}\right)\right)+\sum_{i \in I} \sum_{j \in J} F_{i j} y_{j},
\end{aligned}
$$

where $V_{i j k-1} y_{i j k} \leq x_{i j k} \leq V_{i j k} y_{i j k}, \forall i, \forall j, \forall k$.

If the incremental discount scheme is offered by suppliers, then the company may determine the lower bounds for purchasing quantities with the following additional constraint (17) which enforces the minimum purchasing quantities assigned to each supplier for each product are greater than or equal to the percentage $(u)$ of demand of the respective product. The percentage reflects the DM's preferences based on the business relationship with suppliers and the company [36]:

$$
\sum_{k \in K} x_{i j k} \geq u D_{i}, \quad \forall i
$$

When suppliers offer a volume discount schemes, the above formulation can be modified with formulation (18) instead of (1):

$$
\operatorname{Min} z_{1}=\sum_{i \in I} \sum_{j \in J} \sum_{k \in K}\left(1-d_{i j k}\right) v_{i j k}+\sum_{i \in I} \sum_{j \in J} F_{i j} y_{j},
$$

where $\sum_{i} \sum_{k} v_{i j k}=\sum_{i} \sum_{k} p_{i j k} x_{i j k} \forall j$.

\section{Preliminary Definitions}

Consider the fuzzy multiple objective programming problem (19) with $l$ fuzzy objective functions and $s$ fuzzy constraints:

$$
\begin{array}{ll}
\text { Find } & x \\
\text { s.t. } & c_{k} x \widetilde{\leq} z_{k} \quad k \in I \\
& a_{r} x \cong b_{r} \quad r \in T \\
& x \in X,
\end{array}
$$

where

(i) $X$ is a set of deterministic linear constraints and sign restrictions;

(ii) $c_{k} x=\sum_{i=1}^{n} c_{k i} x_{i} k=1, \ldots, l ; a_{r} x=\sum_{i=1}^{n} a_{r i} x_{i} r=$ $1, \ldots, s$ 
(iii) for $k \in I, z_{k}$ is the imprecise aspiration level for the $k$ th objective function;

(iv) $z_{k} \in\left[z_{k}^{L}, z_{k}^{U}\right]$ denote the imprecise lower and upper, respectively, bounds for the $k$ th fuzzy objective function. $b_{r} \in\left[b_{r}-\Delta_{r L}, b_{r}+\Delta_{r U}\right]$ denote the imprecise lower and upper, respectively, bounds for the $r$ th fuzzy constraints.

According to fuzzy mathematical programming, each fuzzy objective and constraint are defined in terms of fuzzy subsets with the appropriate membership functions denoted by $\mu_{k}\left(c_{k} x\right)$ for $k \in I$ and $\mu_{r}\left(a_{r} x\right)$ for $r \in T$, respectively. Assuming that membership functions are linear, mathematical definitions are given in (20) and (21). Equation (20) represents linear monotone decreasing membership function $\mu_{k}\left(c_{k} x\right)$ for minimization type objectives with fuzzy aspiration levels and expression (21) is a triangular membership function $\mu_{r}\left(a_{r} x\right)$ for constraints:

$$
\begin{aligned}
& \mu_{k}\left(c_{k} x\right)= \begin{cases}1 & \text { if } c_{k} x \leq z_{k}^{L} \\
\frac{z_{k}^{U}-c_{k} x}{z_{k}^{U}-z_{k}^{L}} & \text { if } z_{k}^{L} \leq c_{k} x \leq z_{k}^{U} \\
0 & \text { if } c_{k} x \geq z_{k}^{U},\end{cases} \\
& \mu_{r}\left(a_{r} x\right)= \begin{cases}\frac{0}{\frac{a_{r} x-\left(b_{r}-\Delta_{r L}\right)}{\Delta_{r L}}} & \text { if } a_{r} x \leq b_{r}-\Delta_{r L} \\
\frac{b_{r}+\Delta_{r U}-a_{r} x}{\Delta_{r U}} & \text { if } b_{r}-\Delta_{r L} \leq a_{r} x \leq a_{r} x \leq b_{r}+b_{r U} \\
0 & \text { if } a_{r} x \geq b_{r}+\Delta_{r U},\end{cases}
\end{aligned}
$$

4.1. Fuzzy Additive Model. Fuzzy additive model based on Tiwari et al.s [17] study for the multiple objective programming model (19) is given in (22). Variables denoted by $\lambda_{k}$ and $\lambda_{r}$ represent achievement levels of fuzzy objective functions and fuzzy constraints, respectively:

$$
\begin{array}{ll}
\max & \frac{\left(\sum_{k=1}^{l} \lambda_{k}+\sum_{r=1}^{s} \lambda_{r}\right)}{(l+s)} \\
\text { s.t. } & \lambda_{k} \leq \mu_{k}\left(c_{k} x\right) \quad k \in I \\
& \lambda_{r} \leq \mu_{r}\left(a_{r} x\right) \quad r \in T \\
& \lambda_{i}, \lambda_{r} \in[0,1] \quad k=1, \ldots, l ; r=1, \ldots, s ; \\
& x \in X .
\end{array}
$$

Fuzzy weighted additive model [17] has the same constraints with the following objective function (23):

$$
\max w_{k} \sum_{k=1}^{l} \lambda_{k}+w_{r} \sum_{r=1}^{s} \lambda_{r}
$$

where $w_{k}$ and $w_{r} \in[0,1]$ and they denote relative weights for each fuzzy criterion, and $\sum_{k} w_{k}+\sum_{r} w_{r}=1$ for $k=1, \ldots, l$; $r=1, \ldots, s$.

4.2. Augmented Max-Min Model. Augmented max-min model (24) based on Lai and Hwang's [18, 19] approach is adapted for model (19) as follows:

$$
\begin{array}{ll}
\max & \lambda+\frac{\left\{\sum_{k=1}^{l} \mu_{k}\left(c_{k} x\right)+\sum_{r=1}^{s} \mu_{r}\left(a_{r} x\right)\right\}}{(l+s)} \\
\text { s.t. } & \lambda \leq \mu_{k}\left(c_{k} x\right), \quad k=1,2, \ldots, l \\
& \lambda \leq \mu_{r}\left(a_{r} x\right) \quad r=1,2, \ldots, s \\
& x \in X \\
& \lambda \in[0,1] .
\end{array}
$$

Variable $\lambda$ represents the minimum satisfaction degree and is defined as in (25):

$\min _{k, r}\left\{\mu_{k}\left(c_{k} x\right), \mu_{r}\left(a_{r} x\right)\right\}, \quad$ for $k=1,2, \ldots, l ; r=1,2, \ldots, s$.

4.3. Chen and Tsai's Fuzzy Model. Chen and Tsai's [20] fuzzy model is adopted for model (19) in (26). Variables denoted by $\lambda_{k}$ and $\lambda_{r}$ represent achievement levels of fuzzy objective functions and fuzzy constraints, respectively, defined in model (22). Parameters $\alpha_{k}$ and $\alpha_{r}$ represent the minimum acceptable achievement levels for the $k$ th objective, $r$ th constraint, respectively, determined by the DM. This model allows the DM to assign explicitly a desirable achievement degree for each fuzzy aspiration [20]:

$$
\begin{array}{ll}
\max & \frac{\left(\sum_{k=1}^{l} \lambda_{k}+\sum_{r=1}^{s} \lambda_{r}\right)}{(l+s)} \\
\text { s.t. } & \lambda_{k} \leq \mu_{k}\left(c_{k} x\right) \quad k \in I \\
& \lambda_{r} \leq \mu_{r}\left(a_{r} x\right) \quad r \in T \\
& \lambda_{k} \geq \alpha_{k}, \quad k=1, \ldots, l \\
& \lambda_{r} \geq \alpha_{r} \quad r=1, \ldots, s \\
& x \in X \quad \\
& \alpha_{k}, \alpha_{r}, \alpha_{p}, \lambda_{i}, \lambda_{r}, \lambda_{p} \in[0,1] \\
& k=1, \ldots, l ; \quad r=1, \ldots, s ; \\
& x \in X .
\end{array}
$$

\section{Interactive Solution Methodology [40]}

To solve the multiple objective sourcing problem with multiple items in discount environment, previously proposed interactive algorithm [40] is performed based on the assumptions of the problem. The flowchart of the interactive approach is modified for the current study and included in 
the appendix. Case (b) and case (c) mentioned in the flowchart are adequate for the assumptions of the problem in this study. Surely, the other two cases can be considered based on the problem requirements. In the current study it is assumed that fuzzy demand level(s) are fuzzy triangular number(s). The followed steps are summarized below.

(1) Construct the multiple objective model ((1) to (15)).

(2) Determine fuzzy parameters as aspiration levels of objectives and/or fuzzy demand level(s).

(3) If both aspiration levels of objectives and/or demand level(s) are fuzzy then construct the linear or piecewise linear membership functions for each fuzzy goal (20) and/or each fuzzy demand (21).

(4) If the model has only fuzzy demand level(s) for each or some product(s), considering $b_{r}-\Delta_{r L}$ and $b_{r}+\Delta_{r U}$ one at a time, solve the mathematical model defined with (1) to (15) and find the ideal solutions for each objective. Construct two payoff tables. Determine the lower and upper bounds for each objective. Ask the DM whether bounds are acceptable. Update bounds as $s($ he) wishes. Construct linear/piecewise linear membership function for each objective.

(5) If there are equal or numerically close relative weights for fuzzy aspirations go to step (6); otherwise go to step (7).

(6) Construct and solve augmented max-min model (24). Present the fuzzy optimal solution(s) to the DM. If the DM is satisfied then stop. Else, go to step (8).

(7) If there are unequal relative weights for fuzzy aspirations then construct and solve fuzzy weighted additive model (23). Present the fuzzy optimal solution(s) to the DM. If the DM is satisfied then stop. Else go to step (8).

(8) Ask the DM for the minimum acceptable aspiration level for each fuzzy objective and/or fuzzy constraint. During the determination process, the DM will take aspiration levels obtained in step (6)/(7) as references for minimum acceptable aspiration levels. Construct and solve Chen and Tsai's fuzzy model (26). Present the fuzzy optimal solution(s) to the DM. If the DM is satisfied then stop. Else if the fuzzy model parameters are both fuzzy aspirations of objectives and fuzzy right hand side constants go to step (3).

\section{Illustrative Example}

The following example problem is from Nazari-Shirkouhi et al.'s study [57] for sourcing and order allocation problem with multiple items and multiple suppliers. The aim of the example problem is to select appropriate suppliers based on three pur-chasing criteria which are price, quality, and service level for supplying two products. Each supplier offers "all units" price breaks. The prices are in the three price levels for each supplier. The percentage of the rejected items and late deliveries, suppliers' capacities, and quantity levels with offered prices are provided in Table 3. The original data includes quota flexibility, service level, and rating values of each supplier for each item (Table 4). To solve the model, Nazari-Shirkouhi et al. [57] performed an experimentation in which objectives are unified by using weighted sum of normalized objectives.

In this current study we modified the data set with fuzzy aspirations and fuzzy demand levels. The approach based on the payoff tables proposed in [40] is utilized for the determination of the lower and upper bound during the construction of the membership functions. The fuzzy model with the obtained bounds maintains the solution occurring in the feasible region of the main problem. Furthermore it gives a Pareto optimal solution.

Step (1): multiple objective sourcing and order allocation model is constructed ((1) to (15)).

Step (2-3): fuzzy triangular number for fuzzy demand of each product is defined with $\left[b_{r}-\Delta_{r L}, b_{r}, b_{r}+\Delta_{r U}\right]$.

Step (4): considering lower bounds and upper bounds of demand levels, one at a time, the corresponding mathematical model defined with (1) to (15) in Section 3 is constructed and ideal solutions for each objective are found. Constructed payoff tables are Tables 5 and 6.

The lower and upper bounds for each objective according to payoff tables are determined as $\left(z_{1}^{L}, z_{1}^{U}\right)=$ $(21135,28810),\left(z_{2}^{L}, z_{2}^{U}\right)=(41.60,68.60),\left(z_{3}^{L}, z_{3}^{U}\right)=$ $(34.60,57.40)$. Bounds are assumed as acceptable for the DM. The related membership functions are constructed by using (20) equations with the mentioned bounds of aspirations. Bounds are assumed as acceptable for the DM. Go to step (5).

Step (5-6): it is assumed that there are equal or numerically close relative weights for fuzzy aspirations, and then the solution of the constructed augmented maxmin model (24) for the illustrative example is given in Table 5. For this case it is assumed that the DM is not satisfied with aspiration levels mentioned in Table 7 column 2 to go to step (8).

Step (7): assume that there are unequal weights for fuzzy aspirations; then the solution of the constructed fuzzy weighted additive model (23) for the illustrative example is given in Table 8 . Weight vector is defined for three different cases as $w^{1}, w^{2}, w^{3}$. Assume that $\mathrm{DM}$ is not satisfied; then go to step (8).

Step (8): fuzzy additive model solution (22) in Table 7 column 3 can be presented to the DM as references for his/her minimum acceptable aspiration levels which are assumed as $(0.5,0.5,0.5)$ for $\alpha_{k}, k=1,2,3$, and (0.5) for $\alpha_{r} r=1,2,3,4,5$ as the first case. Then Chen and Tsai's fuzzy model (24) is constructed and solved (Table 7 columns four and five). Minimum acceptable aspiration levels attained by the DM are assumed as $(0.7,0.5,0.5)$ for $\alpha_{k}, k=1,2,3$, and $(0.5,0.7,0.5,0.5$, $0.7)$ for $\alpha_{r} r=1,2,3,4,5$ as the second case. Then Chen and Tsai's fuzzy model (14) is constructed and solved (Table 7 columns six and seven). 
TABLE 3: Data for the illustrative example (modified from [57]).

\begin{tabular}{|c|c|c|c|c|c|c|c|c|}
\hline Product $i$ & Fuzzy demand $\left[b_{r}-\Delta_{r L}, b_{r}, b_{r}+\Delta_{r U}\right]$ & Supplier $j$ & $F_{i j}$ & $q_{i j}(\%)$ & $t_{i j}(\%)$ & $C_{i j}$ & $P_{i j 1}, P_{i j 2}, P_{i j 3}(\$)$ & $V_{i j 0}, V_{i j 2}, V_{i j 3}$ \\
\hline \multirow{4}{*}{1} & \multirow{4}{*}[750,700,650]{} & 1 & 800 & 4 & 1 & 1300 & $18,17.5,17$ & $0,100,200$ \\
\hline & & 2 & 750 & 3 & 2 & 1100 & $17,16.5,16$ & $0,120,220$ \\
\hline & & 3 & 600 & 4 & 1 & 1000 & $15,14.5,14$ & $0,150,300$ \\
\hline & & 4 & 650 & 3 & 2 & 900 & $16,15.5,15$ & $0,90,180$ \\
\hline \multirow{3}{*}{2} & \multirow{3}{*}[650,600,550]{} & 1 & 800 & 4 & 2 & 1400 & $6.5,6,5.5$ & $0,80,170$ \\
\hline & & 3 & 600 & 2 & 3 & 1400 & $4,3.5,3$ & $0,60,190$ \\
\hline & & 4 & 650 & 1 & 2 & 1400 & $5,4.5,4$ & $0,90,210$ \\
\hline \multirow{2}{*}{3} & \multirow{2}{*}[500,450,400]{} & 2 & 750 & 2 & 2 & 1300 & $10,9.5,9$ & $0,75,180$ \\
\hline & & 3 & 600 & 5 & 1 & 1200 & $11,10.5,10$ & $0,60,130$ \\
\hline \multirow{4}{*}{4} & \multirow{4}{*}[450,400,350]{} & 1 & 800 & 2 & 3 & 1000 & $8,7.5,7$ & $0,100,180$ \\
\hline & & 2 & 750 & 1 & 3 & 1000 & $12,11.5,11$ & $0,150,300$ \\
\hline & & 3 & 600 & 1 & 4 & 1100 & $10,9.5,9$ & $0,90,160$ \\
\hline & & 4 & 650 & 0 & 2 & 800 & $13,12.5,12$ & $0,150,240$ \\
\hline \multirow{2}{*}{5} & \multirow{2}{*}[430,380,330]{} & 1 & 800 & 2 & 1 & 1200 & $6,5.5,5$ & $0,120,220$ \\
\hline & & 2 & 750 & 2 & 2 & 1300 & $5,4.5,4$ & $0,100,200$ \\
\hline
\end{tabular}

TABLE 4: Quota flexibility, service level, and rating data for the illustrative example [57].

\begin{tabular}{lccccccc}
\hline $\begin{array}{l}\text { Product } \\
i\end{array}$ & $\begin{array}{c}\text { Supplier } \\
j\end{array}$ & $\begin{array}{c}E_{i} \\
(\%)\end{array}$ & $\begin{array}{c}S_{i} \\
(\%)\end{array}$ & $\begin{array}{c}R_{i} \\
(\%)\end{array}$ & $\begin{array}{c}e_{i j} \\
(\%)\end{array}$ & $\begin{array}{c}s_{i j} \\
(\%)\end{array}$ & $\begin{array}{c}r_{i j} \\
(\%)\end{array}$ \\
\hline \multirow{3}{*}{1} & 1 & & 4 & 1 & 3 & 94 & 92 \\
& 2 & 2 & 3 & 2 & 2 & 90 & 95 \\
& 3 & & 4 & 1 & 2 & 94 & 90 \\
& 4 & & 3 & 2 & 5 & 94 & 96 \\
\hline \multirow{3}{*}{3} & 1 & & 4 & 2 & 3 & 91 & 95 \\
& 3 & 2 & 2 & 3 & 3 & 95 & 96 \\
& 4 & & 1 & 2 & 4 & 96 & 96 \\
\hline & 2 & & 2 & 2 & 5 & 95 & 91 \\
4 & 3 & & 5 & 1 & 4 & 95 & 92 \\
\hline & 1 & & 2 & 3 & 4 & 92 & 93 \\
& 2 & 3 & 1 & 3 & 4 & 92 & 93 \\
& 3 & & 1 & 4 & 1 & 95 & 92 \\
& 4 & & 0 & 2 & 1 & 94 & 93 \\
\hline \multirow{3}{*}{5} & 1 & 2 & 2 & 1 & 4 & 91 & 90 \\
& 2 & & 2 & 2 & 4 & 96 & 91 \\
\hline
\end{tabular}

The algorithm is terminated with the assumption that the DM is satisfied with the current fuzzy optimal solution. If it is assumed that DM is not satisfied, then we should go to step (4). It will be carried on steps of the algorithm.

Models (23), (24), and (26) are utilized for the illustrative example and fuzzy optimal solutions are obtained by GAMS computer programming package. Their summaries which are given in Tables 7 and 8 constitute nondominated solutions. When fuzzy additive model solution is investigated, it is observed that the third objective which minimizes the total number of late delivered units and serves in maximizing the service level of purchased items has the least achievement level as 0.496 . This is because the additive model maximizes
TABLe 5: Payoff table (demand level chosen as $b_{r}-\Delta_{r L}$ ).

\begin{tabular}{lccc}
\hline & $z_{1}\left(x_{1}{ }^{*}\right)$ & $z_{2}\left(x_{2}{ }^{*}\right)$ & $z_{3}\left(x_{3}{ }^{*}\right)$ \\
\hline$x_{1}{ }^{*}$ & $21135^{\dagger}$ & 23915 & 25100 \\
$x_{2}{ }^{*}$ & 58.90 & $41.60^{\ddagger}$ & 57.60 \\
$x^{*}{ }^{*}$ & 47 & 45.80 & $34.60^{\#}$ \\
\hline
\end{tabular}

TABle 6: Payoff table (demand level chosen as $b_{r}+\Delta_{r U}$ ).

\begin{tabular}{cccc}
\hline & $z_{1}\left(x_{1}{ }^{*}\right)$ & $z_{2}\left(x_{2}{ }^{*}\right)$ & $z_{3}\left(x_{3}{ }^{*}\right)$ \\
\hline$x_{1}{ }^{*}$ & 25660 & 28623.5 & $28810^{\dagger}$ \\
$x_{2}{ }^{*}$ & 62.50 & 54.1 & $68.60^{\ddagger}$ \\
$x_{3}{ }^{*}$ & $57.40^{\#}$ & 54.41 & 45.60 \\
\hline
\end{tabular}

achievement levels in total. On the other hand augmented max-min model solution maximizes the minimum achievement level as well and it gives more balanced solution. In Table 8 weighted additive model solutions are presented. To determine relative weights is another multiple attribute decision making problem. In this example problem for three different weight sets is considered. In a realistic point of view the DM may not prefer achievement levels less than 0.5. In that case the procedure will carry on with step (8). After presenting additive (/weighted additive) or augmented maxmin model solutions to the DM, Chen and Tsai's fuzzy model provides a preferred solution.

\section{Conclusions and Future Direction}

In this study a multiple sourcing supplier selection problem is considered as a multiple objective linear programming problem. The literature is reviewed for the studies which handle supplier selection by fuzzy multiple objective mathematical programming and they are investigated according to their solution approaches. The detailed literature reviews in the author's previous studies [38-40] lead the construction of 
TABLE 7: Solution summaries to the illustrative example with linear membership functions.

\begin{tabular}{lccccc}
\hline & Augmented max-min model & Additive model & \multicolumn{3}{c}{ Chen and Tsai's fuzzy model } \\
& & & $\alpha_{k} / \alpha_{r}$ & & $\alpha_{k} / \alpha_{r}$ \\
\hline Min $z_{1}$ & 24778 & 24850 & 0.5 & 24860 & 0.7 \\
Min $z_{2}$ & 54.41 & 51.10 & 0.5 & 51.20 & 0.5 \\
$\operatorname{Min} z_{3}$ & 45.43 & 46.01 & 0.5 & 46.00 & 0.5 \\
\hline$\mu_{1}\left(c_{1} x\right)$ & 0.525 & 0.510 & & 0.515 & 45.01 \\
$\mu_{2}\left(c_{2} x\right)$ & 0.526 & 0.648 & & 0.644 & 0.700 \\
$\mu_{3}\left(c_{3} x\right)$ & 0.525 & 0.496 & 0.500 & 0.503 \\
$\mu_{1}\left(a_{1} x\right)$ & 1.000 & 1.000 & 0.5 & 1.000 & 0.5 \\
$\mu_{2}\left(a_{1} x\right)$ & 1.000 & 1.000 & 0.5 & 1.000 & 0.7 \\
$\mu_{3}\left(a_{2} x\right)$ & 1.000 & 1.000 & 0.5 & 1.000 & 0.500 \\
$\mu_{4}\left(a_{3} x\right)$ & 1.000 & 1.000 & 0.5 & 1.000 & 0.5 \\
$\mu_{5}\left(a_{1} x\right)$ & 1.000 & 1.000 & 0.5 & 1.000 & 0.5 \\
\hline
\end{tabular}

TABLE 8: Solution summaries to the illustrative example for fuzzy weighted additive model.

\begin{tabular}{lccc}
\hline & $\begin{array}{c}\text { Additive } \\
\text { model Case 1 }\end{array}$ & $\begin{array}{c}\text { Additive } \\
\text { model Case 2 }\end{array}$ & $\begin{array}{c}\text { Additive } \\
\text { model Case 3 }\end{array}$ \\
\hline $\operatorname{Min} z_{1}$ & 23850 & 25500 & 26000 \\
$\operatorname{Min} z_{2}$ & 55.01 & 54.60 & 47.10 \\
$\operatorname{Min} z_{3}$ & 48.30 & 42.60 & 49.10 \\
\hline$\mu_{1}\left(c_{1} x\right)$ & 0.646 & 0.431 & 0.366 \\
$\mu_{2}\left(c_{2} x\right)$ & 0.500 & 0.519 & 0.796 \\
$\mu_{3}\left(c_{3} x\right)$ & 0.399 & 0.649 & 0.364 \\
\hline$\mu_{1}\left(a_{1} x\right)$ & 1.000 & 1.000 & 1.000 \\
$\mu_{2}\left(a_{1} x\right)$ & 1.000 & 1.000 & 1.000 \\
$\mu_{3}\left(a_{2} x\right)$ & 1.000 & 1.000 & 1.000 \\
$\mu_{4}\left(a_{3} x\right)$ & 1.000 & 1.000 & 1.000 \\
$\mu_{5}\left(a_{1} x\right)$ & 1.000 & 1.000 & 1.000 \\
\hline
\end{tabular}

Case $1 w^{1}(0.25,0.10,0.15,0.10,0.10,0.10,0.10,0.10)$.

Case $2 w^{2}(0.10,0.10,0.25,0.10,0.10,0.10,0.10,0.10)$.

Case $3 w^{3}(0.10,0.25,0.10,0.10,0.10,0.10,0.10,0.10)$.

the current study's literature. However they are not interested in discount strategies. Herein the literature is also reviewed for the discount strategies. A clear classification is constructed for the discount schemes mentioned in the literature (Table 1) with references. The studies which handle sourcing problem by fuzzy multiple objective mathematical programming in discount environment are also investigated and criticized based on their solution approaches (Table 2).

Detailed review reveals that there is no multiple itemsingle period fuzzy model for multiple objective sourcing problem in discount environment except for the NazariShirkouhi et al.s [57] in the literature. The current study proposes an enhanced mathematical model by additional constraints for the quota flexibility, service level, and rating values for each product, by adding modification requirements of the model for the different discount schemes and by considering fuzziness not only of aspiration levels of objectives but also of demand levels. Furthermore the interactive solution approach utilized in the current study gives opportunities which go beyond to all other approaches employed for the problem, because it [40] comes handy not only to reach a nondominated solution which satisfies the DM's preferred achievement levels but also to consider the different cases for the fuzzy parameter occurrences and the DM's different bias on the nondominated solution.

This study provides a realistic multiple objective sourcing and order allocation model which considers three objective functions as minimization of costs, maximization of quality, and maximization of on-time delivery with fuzzy aspiration levels, respectively, and/or fuzzy demand. To keep the business relationship with suppliers the model contains restrictions on the number of suppliers employed by the buyer with a maximum number quota for each product. When suppliers offer incremental and volume discount schemes, the required modifications on the model are also investigated. The model is employed to construct fuzzy mathematical models which give nondominated solutions. Each possible fuzzy parameter is represented mathematically by using a linear membership function. For fuzzy demand levels, fuzziness is defined by triangular membership functions which can be isosceles or unbalanced. In the utilized interactive procedure three well known fuzzy mathematical models are employed based on the problem requirements. Both fuzzy additive and augmented max-min models give nondominated solutions. Augmented max-min model solution is balanced additionally. Chen and Tsai's fuzzy model with the interactive steps of the solution approach gives an opportunity to the DM to obtain her/his own preferred achievement levels for the objectives and for demand levels. Consideration of fuzziness makes the obtained nondominated solution implementable for the real cases.

In the relatively scarce studies which try to deal with the sourcing and order allocation problem with multiple items, multiple criteria, and fuzzy parameters in discount environment simultaneously, this study provides a realistic mathematical model and promising strategies to satisfy the purchasing managers' (DM's) preferences which can be a balanced solution or there can be preferred achievements for each of the fuzzy aspirations to be satisfied, as long as the obtained result is a nondominated solution. 


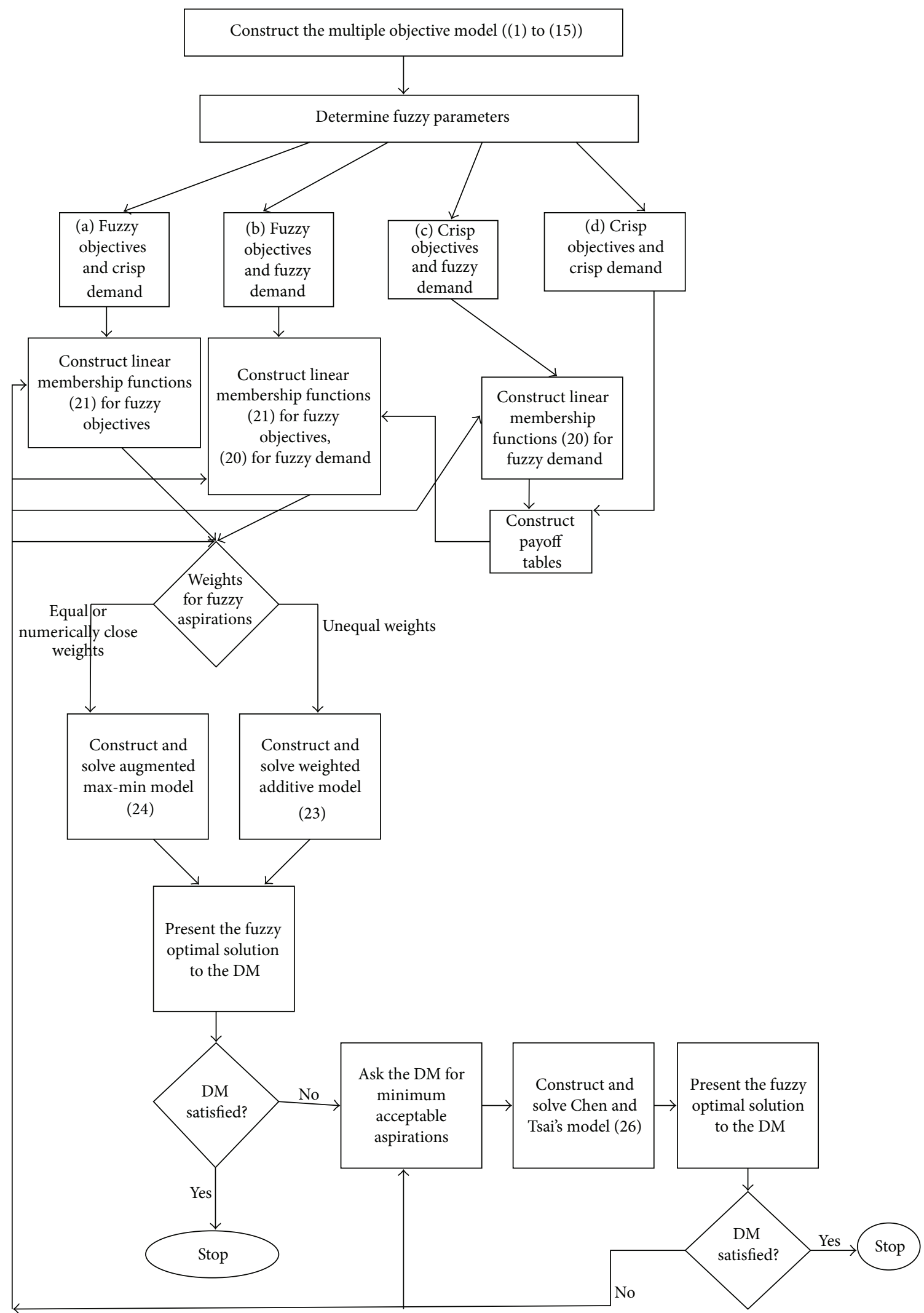

FIGURE 1: Flowchart of the interactive approach from [40] with modifications for the current study. 
For the planned future work, fuzziness in each supplier's capacity is going to be considered. In that case sourcing and order allocation problem will become a nonlinear programming problem.

\section{Appendix}

See Figure 1.

\section{Conflict of Interests}

The author declares that there is no conflict of interests regarding the publication of this paper.

\section{Acknowledgment}

The author would like to express their special thanks to Professor Dr. Tsan-Ming Choi for his valuable comments and critics which help them to highlight the originality of this study.

\section{References}

[1] G. W. Dickson, "An analysis of vendor selection systems and decisions," Journal of Purchasing, vol. 2, no. 1, pp. 5-17, 1966.

[2] F. Arikan, "Fuzzy decision making for multiple sourcing and order allocation with price discounts," in Proceedings of the Joint International Symposium on the Social Impacts of the Development in Information Manufacturing and Service Systems (CIE '44/IMSS '14), Istanbul, Turkey, October 2014.

[3] D. Sirias and S. Mehra, "Quantity discount versus lead timedependent discount in an inter-organizational supply chain," International Journal of Production Research, vol. 43, no. 16, pp. 3481-3496, 2005.

[4] N. Aissaoui, M. Haouari, and E. Hassini, "Supplier selection and order lot sizing modeling: a review," Computers and Operations Research, vol. 34, no. 12, pp. 3516-3540, 2007.

[5] G. J. Burke, J. Carrillo, and A. J. Vakharia, "Heuristics for sourcing from multiple suppliers with alternative quantity discounts," European Journal of Operational Research, vol. 186, no. 1, pp. 317-329, 2008.

[6] Y. Qin, R. Wang, A. J. Vakharia, Y. Chen, and M. M. Seref, "The newsvendor problem: review and directions for future research," European Journal of Operational Research, vol. 213, no. 2, pp. 361-374, 2011.

[7] A. A. Sadrian and Y. S. Yoon, "Business volume discount a new perspective on discount pricing strategy," International Journal of Purchasing and Materials Management, vol. 28, pp. 43-46, 1992.

[8] A. A. Sadrian and Y. S. Yoon, "Procurement decision support system in business volume discount environments," Operations Research, vol. 42, no. 1, pp. 14-23, 1994.

[9] E. C. Rosenthal, J. L. Zydiac, and S. S. Chaudhry, "Vendor selection with bundling," Decision Sciences, vol. 26, no. 1, pp. 3548, 1995.

[10] J. Sarkis and J. H. Semple, "Vendor selection with bundling: a comment," Decision Sciences, vol. 30, no. 1, pp. 265-271, 1999.
[11] N. N. Murthy, S. Soni, and S. Ghosh, "A framework for facilitating sourcing and allocation decisions for make-to-order items," Decision Sciences, vol. 35, no. 4, pp. 609-636, 2004.

[12] I. Turner, "An independent system for the evaluation of contract tenders," Journal of the Operational Research Society, vol. 39, no. 6, pp. 551-561, 1988.

[13] R. J. Tersine and S. Barman, "Economic inventory/transport lot sizing with quantity and freight rate discounts," Decision Sciences, vol. 22, no. 5, pp. 1171-1191, 1991.

[14] T. H. Burwell, D. S. Dave, K. E. Fitzpatrick, and M. R. Roy, "Economic lot size model for price-dependent demand under quantity and freight discounts," International Journal of Production Economics, vol. 48, no. 2, pp. 141-155, 1997.

[15] J. Moussourakis and C. Haksever, "Models for ordering multiple products subject to multiple constraints, quantity and freight discounts," American Journal of Operations Research, vol. 3, pp. 521-535, 2013.

[16] S. A. Torabi and E. Hassini, "Multi-site production planning integrating procurement and distribution plans in multiechelon supply chains: an interactive fuzzy goal programming approach," International Journal of Production Research, vol. 47, no. 19, pp. 5475-5499, 2009.

[17] R. N. Tiwari, S. Dharmar, and J. R. Rao, "Fuzzy goal programming - an additive model," Fuzzy Sets and Systems, vol. 24, no. 1, pp. 27-34, 1987.

[18] Y. J. Lai and C. L. Hwang, "A new approach to some possibilistic linear programming problems," Fuzzy Sets and Systems, vol. 49, no. 2, pp. 121-133, 1992.

[19] Y.-J. Lai and C. L. Hwang, Fuzzy Multiple Objective Decision Making-Methods and Applications, vol. 404 of Lecture Notes in Economics and Mathematical Systems, Springer, Berlin, Germany, 1996.

[20] L.-H. Chen and F.-C. Tsai, "Fuzzy goal programming with different importance and priorities," European Journal of Operational Research, vol. 133, no. 3, pp. 548-556, 2001.

[21] C. A. Weber, J. R. Current, and W. C. Benton, "Vendor selection criteria and methods," European Journal of Operational Research, vol. 50, no. 1, pp. 2-18, 1991.

[22] Z. Degraeve, E. Labro, and F. Roodhooft, "An evaluation of vendor selection models from a total cost of ownership perspective," European Journal of Operational Research, vol. 125, no. 1, pp. 34-58, 2000.

[23] L. De Boer, E. Labro, and P. Morlacchi, "A review of methods supporting supplier selection," European Journal of Purchasing and Supply Management, vol. 7, no. 2, pp. 75-89, 2001.

[24] W. Ho, X. Xu, and P. K. Dey, "Multi-criteria decision making approaches for supplier evaluation and selection: a literature review," European Journal of Operational Research, vol. 202, no. 1, pp. 16-24, 2010.

[25] D. Peidro, J. Mula, R. Poler, and F. C. Lario, "Quantitative models for supply chain planning under uncertainty," International Journal of Advanced Manufacturing Technology, vol. 43, no. 34, pp. 400-420, 2009.

[26] J. Chai, J. N. K. Liu, and E. W. T. Ngai, "Application of decisionmaking techniques in supplier selection: a systematic review of literature," Expert Systems with Applications, vol. 40, no. 10, pp. 3872-3885, 2013.

[27] T.-Y. Wang and Y.-H. Yang, "A fuzzy model for supplier selection in quantity discount environments," Expert Systems with Applications, vol. 36, no. 10, pp. 12179-12187, 2009. 
[28] F. Arikan and Y. S. Küçükçe, "A supplier selection-evaluation problem for the purchase action and its solution," Journal of the Faculty of Engineering and Architecture of Gazi University, vol. 27, no. 2, pp. 255-264, 2012.

[29] W. Xia and Z. Wu, "Supplier selection with multiple criteria in volume discount environments," Omega, vol. 35, no. 5, pp. 494504, 2007.

[30] A. H. I. Lee, H.-Y. Kang, and C.-T. Chang, "Fuzzy multiple goal programming applied to TFT-LCD supplier selection by downstream manufacturers," Expert Systems with Applications, vol. 36, no. 3, pp. 6318-6325, 2009.

[31] T. Sawik, "Single vs. multiple objective supplier selection in a make to order environment," Omega, vol. 38, no. 3-4, pp. 203212, 2010.

[32] C. A. Weber and J. R. Current, "A multiobjective approach to vendor selection," European Journal of Operational Research, vol. 68, no. 2, pp. 173-184, 1993.

[33] C. A. Weber, J. Current, and A. Desai, "An optimization approach to determining the number of vendors to employ," Supply Chain Management, vol. 5, no. 2, pp. 90-98, 2000.

[34] N.-E. Dahel, "Vendor selection and order quantity allocation in volume discount environments," Supply Chain Management, vol. 8, no. 4, pp. 335-342, 2003.

[35] S. Pokharel, "A two objective model for decision making in a supply chain," International Journal of Production Economics, vol. 111, no. 2, pp. 378-388, 2008.

[36] W. C. Tsai and C. H. Wang, "Decision making of sourcing and order allocation with price discounts," Journal of Manufacturing Systems, vol. 29, no. 1, pp. 47-54, 2010.

[37] J. Rezaei and M. Davoodi, "Multi-objective models for lot-sizing with supplier selection," International Journal of Production Economics, vol. 130, no. 1, pp. 77-86, 2011.

[38] F. Arikan, "A fuzzy solution approach for multi objective supplier selection," Expert Systems with Applications, vol. 40, no. 3, pp. 947-952, 2013.

[39] F. Arikan, "A two-phased additive approach for multiple objective supplier selection with fuzzy demand level," Journal of Multiple-Valued Logic and Soft Computing, vol. 22, pp. 373-385, 2014.

[40] F. Arikan, "An interactive solution approach for multiple objective supplier selection problem with fuzzy parameters," Journal of Intelligent Manufacturing, 2013.

[41] H.-J. Zimmermann, "Fuzzy programming and linear programming with several objective functions," Fuzzy Sets and Systems, vol. 1, no. 1, pp. 45-55, 1978.

[42] M. Kumar, P. Vrat, and R. Shankar, "A fuzzy goal programming approach for vendor selection problem in a supply chain," Computers and Industrial Engineering, vol. 46, no. 1, pp. 69-85, 2004.

[43] M. Kumar, P. Vrat, and R. Shankar, "A fuzzy programming approach for vendor selection problem in a supply chain," International Journal of Production Economics, vol. 101, no. 2, pp. 273-285, 2006

[44] D. Özgen, S. Önüt, B. Gülsün, U. R. Tuzkaya, and G. Tuzkaya, "A two-phase possibilistic linear programming methodology for multi-objective supplier evaluation and order allocation problems," Information Sciences, vol. 178, no. 2, pp. 485-500, 2008.

[45] A. Amid, S. H. Ghodsypour, and C. O'Brien, "Fuzzy multiobjective linear model for supplier selection in a supply chain,"
International Journal of Production Economics, vol. 104, no. 2, pp. 394-407, 2006.

[46] A. Amid, S. H. Ghodsypour, and C. O’Brien, "A weighted additive fuzzy multiobjective model for the supplier selection problem under price breaks in a supply chain," International Journal of Production Economics, vol. 121, no. 2, pp. 323-332, 2009.

[47] F. Faez, S. H. Ghodsypour, and C. O’Brien, "Vendor selection and order allocation using an integrated fuzzy case-based reasoning and mathematical programming model," International Journal of Production Economics, vol. 121, no. 2, pp. 395-408, 2009.

[48] E. J. Wang, Y. C. Chen, W. S. Wang, and T. S. Su, "Analysis of outsourcing cost-effectiveness using a linear programming model with fuzzy multiple goals," International Journal of Production Research, vol. 48, no. 2, pp. 501-523, 2010.

[49] C.-Y. Ku, C.-T. Chang, and H.-P. Ho, “Global supplier selection using fuzzy analytic hierarchy process and fuzzy goal programming," Quality \& Quantity, vol. 44, no. 4, pp. 623-640, 2010.

[50] A. Yücel and A. F. Güneri, "A weighted additive fuzzy programming approach for multi-criteria supplier selection," Expert Systems with Applications, vol. 38, no. 5, pp. 6281-6286, 2011.

[51] M. Díaz-Madroñero, D. Peidro, and P. Vasant, "Vendor selection problem by using an interactive fuzzy multi-objective approach with modified S-curve membership functions," Computers \& Mathematics with Applications, vol. 60, no. 4, pp. 1038-1048, 2010.

[52] D. D. Wu, Y. Zhang, and D. L. Olson, "Fuzzy multi-objective programming for supplier selection and risk modeling: a possibility approach," European Journal of Operational Research, vol. 200, no. 3, pp. 774-787, 2010.

[53] E. S. Lee and R.-J. Li, "Fuzzy multiple objective programming and compromise programming with Pareto optimum," Fuzzy Sets and Systems, vol. 53, no. 3, pp. 275-288, 1993.

[54] R. J. Dolan, "Quantity discounts: managerial issues and research opportunities," Marketing Science, vol. 6, no. 1, pp. 1-23, 1987.

[55] W. C. Benton and S. Park, "A classification of literature on determining the lot size under quantity discounts," European Journal of Operational Research, vol. 92, no. 2, pp. 219-238, 1996.

[56] M. Setak, S. Sharifi, and A. Alimohammadian, "Supplier selection and order allocation models in supply chain management: a review," World Applied Sciences Journal, vol. 18, no. 1, pp. 5572, 2012.

[57] S. Nazari-Shirkouhi, H. Shakouri, B. Javadi, and A. Keramati, "Supplier selection and order allocation problem using a two-phase fuzzy multi-objective linear programming," Applied Mathematical Modelling, vol. 37, no. 22, pp. 9308-9323, 2013.

[58] H.-Y. Kang and A. H. I. Lee, "Inventory replenishment model using fuzzy multiple objective programming: a case study of a high-tech company in Taiwan," Applied Soft Computing Journal, vol. 10, no. 4, pp. 1108-1118, 2010.

[59] J. Razmi and E. Maghool, "Multi-item supplier selection and lot-sizing planning under multiple price discounts using augmented $\varepsilon$-constraint and Tchebycheff method," International Journal of Advanced Manufacturing Technology, vol. 49, no. 14, pp. 379-392, 2010.

[60] S. A. Torabi and E. Hassini, "An interactive possibilistic programming approach for multiple objective supply chain master planning," Fuzzy Sets and Systems, vol. 159, no. 2, pp. 193-214, 2008 . 
[61] B. M. Werners, "Aggregation models in mathematical programming," in Mathematical Models for Decision Support, G. Mitra, Ed., vol. 48 of NATO ASI Series, pp. 295-305, Springer, Berlin, Germany, 1988.

[62] F. Arikan, "A modified augmented max min model for weighted fuzzy goal programming," Journal of Intelligent and Fuzzy Systems, vol. 27, no. 1, pp. 339-350, 2013. 


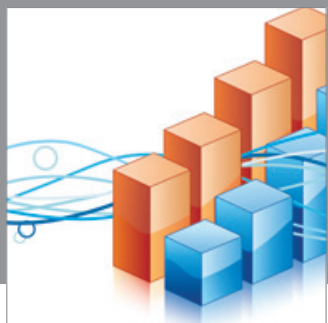

Advances in

Operations Research

mansans

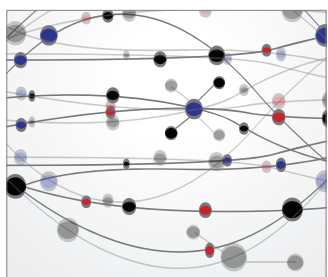

The Scientific World Journal
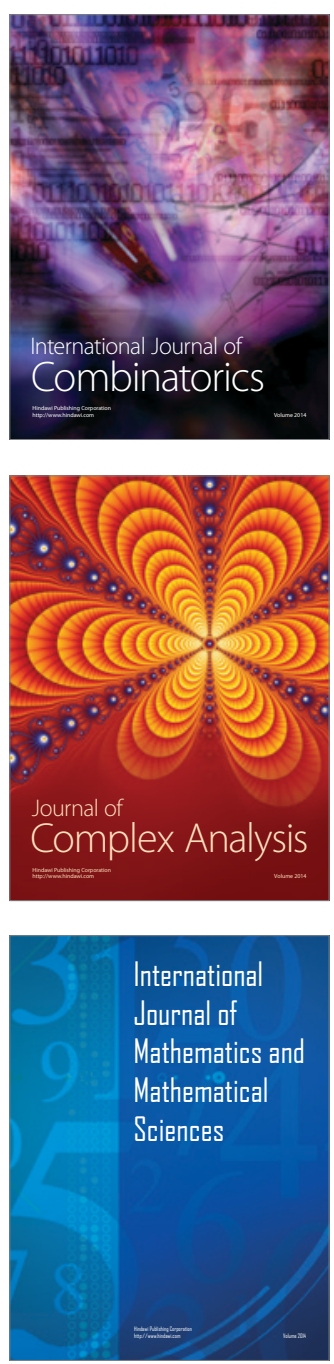
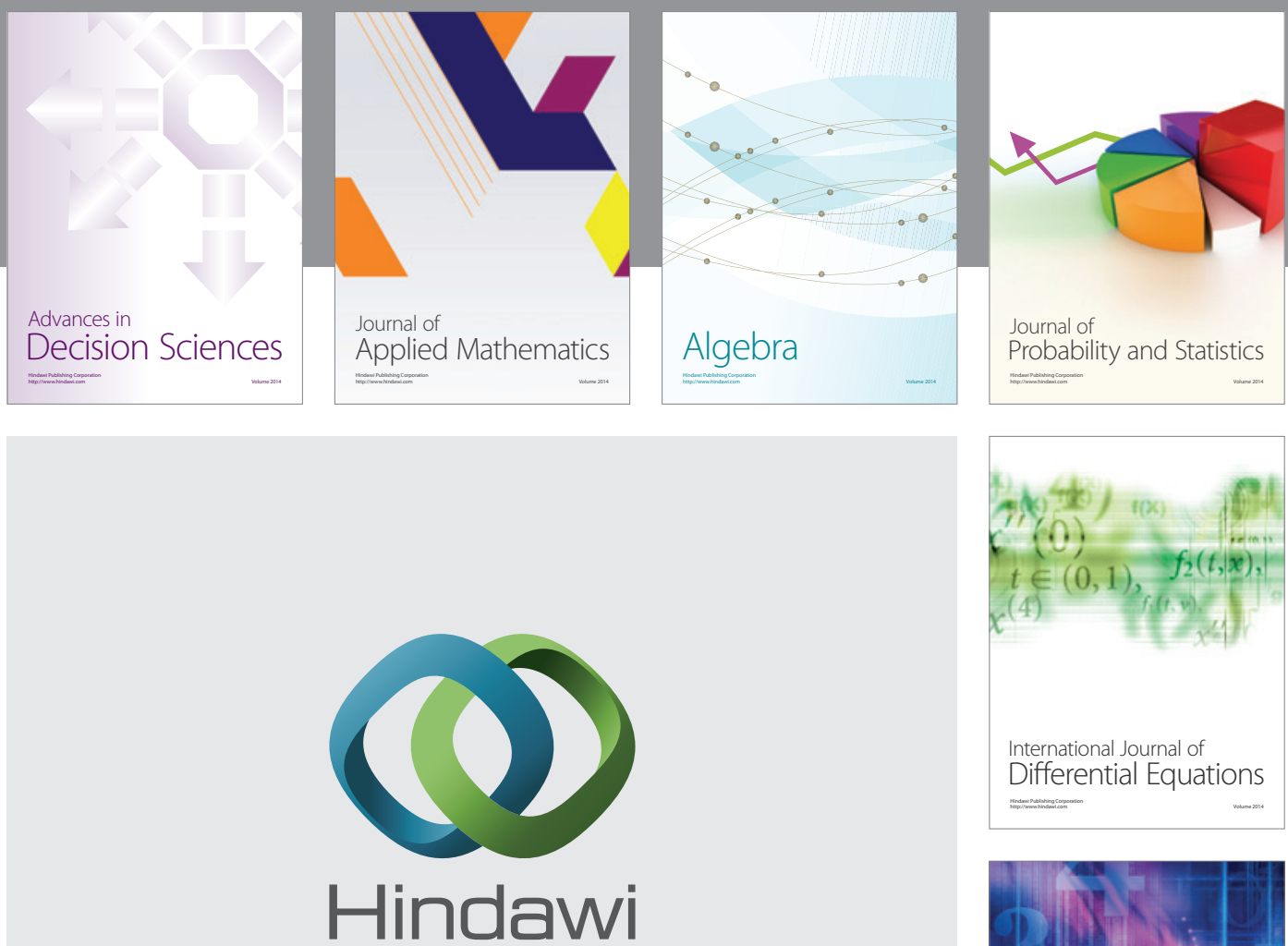

Submit your manuscripts at http://www.hindawi.com
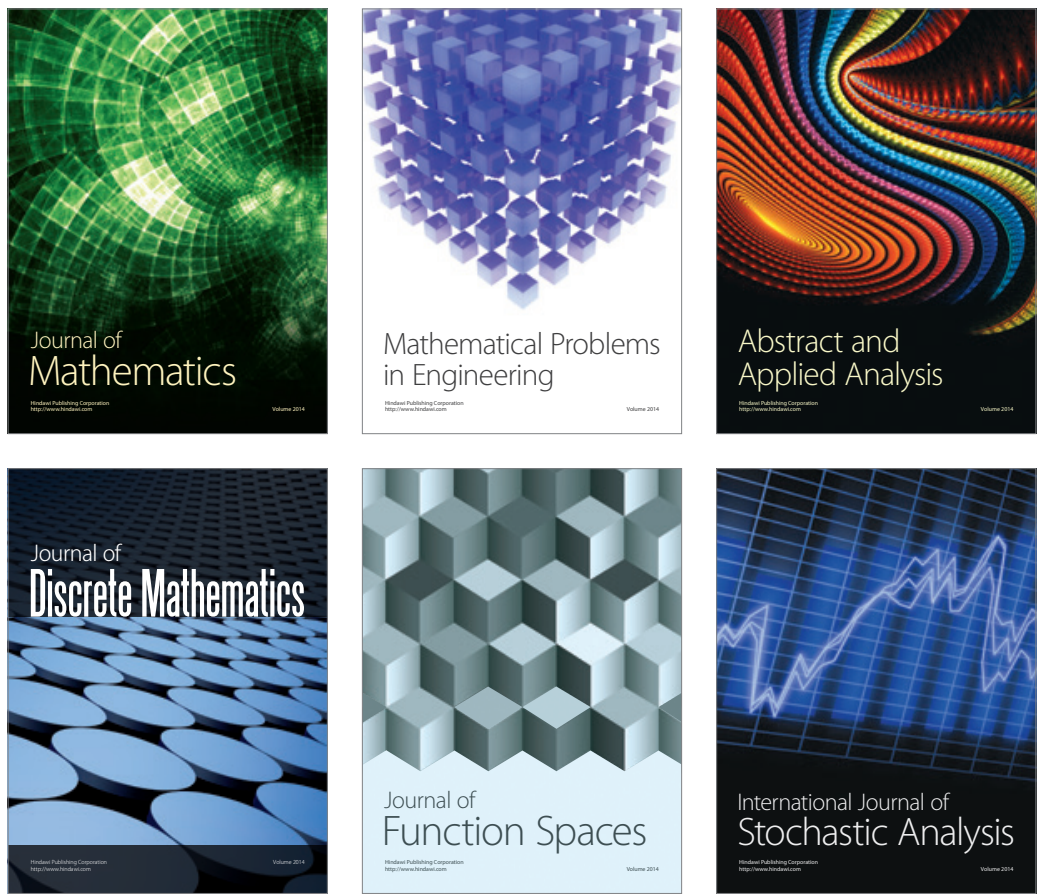

Journal of

Function Spaces

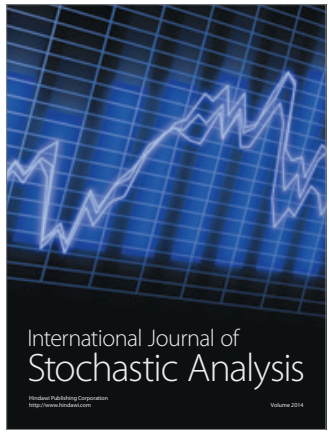

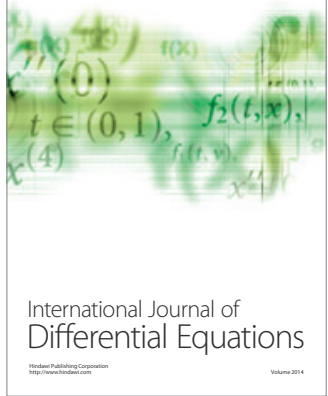
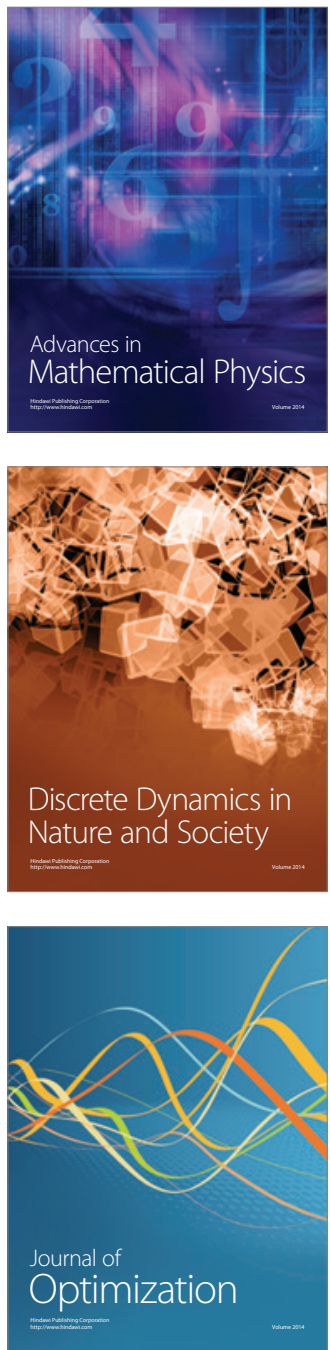